\title{
Origin of hepatocellular carcinoma recurring after allotransplantation revealed by microsatellite analysis
}

\author{
H Pfeiffer, C Ortmann, A Klein, B Brinkmann
}

\begin{abstract}
A hepatocellular carcinoma was resected from a liver allotransplant after the patient's original organ had been removed because of a liver carcinoma. DNA analysis was performed to explore the origin of the carcinoma cells. DNA extracted from the carcinoma tissue, from the carcinoma free liver tissue, and from other cells of the recipient underwent polymerase chain reaction amplification for seven microsatellite systems and the $X-Y$ amelogenin system. The allelic pattern from the carcinoma tissue was identical with that from the patient and differed from the DNA profile of the liver tissue. The result confirmed the assumption that the carcinoma tissue had originated from the patient and not from the donor.

(F Clin Pathol 1997;50:792-794)
\end{abstract}

Keywords: microsatellite analysis; recurrent hepatocellular carcinoma; short tandem repeats

Microsatellite polymorphisms are an abundant class of DNA in the human genome, also known as short tandem repeats (STRs). STRs usually consist of tandemly repeated sequences of 2-5 base pairs where the alleles differ in the number of the repeated units and their fragment length is mostly less than 350 base pairs. ${ }^{1}$ Therefore, they can easily be amplified from highly degraded samples using polymerase chain reaction (PCR). ${ }^{2}$ They are highly polymorphic and inherited in a stable manner. ${ }^{3}$

The incidence of recurrence of a hepatocellular carcinoma after liver transplantation is about $50 \%$ dependent on the stage of the primary tumour. ${ }^{4}$ The five year relapse rate of haematologic malignancies after bone marrow transplantation is similar. ${ }^{5}$ A recurrent tumour after transplantation can originate from recipient or donor tissue. The incidence of the latter increases with time after transplantation. To increase our understanding of the biology and aetiology of such tumours, we investigated a case of de novo occurrence of a hepatocellular carcinoma in a liver allotransplant. We applied DNA technology to elucidate whether the carcinoma tissue had originated from the donor or was a metastasis of the original tumour in the recipient.

\section{Case report}

A 42 year old white woman received a liver transplant because of hepatocellular carcinoma. The donor of the liver was male but the
DNA type was unknown. After six months of convalescence a new liver carcinoma was diagnosed in the recipient, which was resected and formalin fixed.

\section{PATHOLOGY FINDINGS}

Macroscopically a soft nodule $(3.5 \times 3 \mathrm{~cm})$, yellow-brown in colour, in parts sharply defined in others not clearly demarcated, with haemorrhage in the periphery was found within the resected liver lobe. The histological examination revealed a highly differentiated hepatocellular carcinoma with trabecular growth, peripherial infiltration of the liver tissue, and granulocytic demarcated central necrosis (fig 1). Regional nodal and metastatic disease was not diagnosed.

DNA EXTRACTION, QUANTIFICATION, AND AMPLIFICATION

After five days of formalin fixation the tissue was further microdissected to separate the carcinoma from carcinoma free tissue. Both components were rechecked by histological examination. DNA was extracted from organ and tumour tissue by Chelex 100 extraction $^{6}$ and classic phenol-chloroform extraction after proteinase $\mathrm{K}$ incubation. ${ }^{7}$ The latter method resulted in higher DNA yields and was therefore used while all other samples were Chelex extracted. PCR amplification was carried out using published protocols for the STR systems HumACTBP $2,{ }^{8}$ HumTH01, ${ }^{8}$ HumVWA, ${ }^{9}$ HumFES/FPS, ${ }^{10}$ HumFGA, ${ }^{11}$ HumCD4, ${ }^{12}$ and for the $\mathrm{X}-\mathrm{Y}$ homologous gene amelogenin. ${ }^{13}$

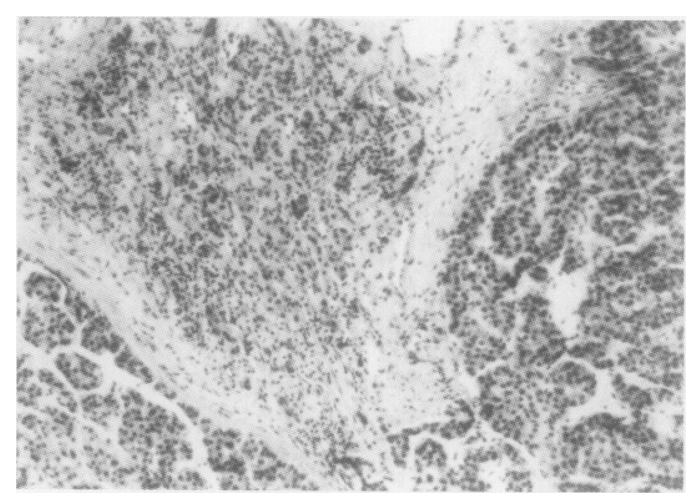

Figure 1 Highly differentiated hepatocellular carcinoma in the transplanted liver with trabecular growth, peripherial infiltration of the liver tissue, and granulocytic demarcated central necrosis. 
Table 1 Allele designation for all systems. In cases of mixed allele patterns the stronger bands are printed in bold characters

\begin{tabular}{lllll}
\hline Locus & $\begin{array}{l}\text { Sample I } \\
\text { Liver (male donor) }\end{array}$ & $\begin{array}{l}\text { Sample II } \\
\text { Carcinoma in donor } \\
\text { liver }\end{array}$ & $\begin{array}{l}\text { Sample III } \\
\text { Recipient } \\
\text { (female) }\end{array}$ & $\begin{array}{l}\text { IV Reconstructed } \\
\text { donor patterns }\end{array}$ \\
\hline HumVWA & $\mathbf{1 6 / 1 7 / 1 9}$ & 16 & 16 & $17 / 19$ \\
HumTH01 & $\mathbf{9 / 9 . 3}$ & $9 / 9.3$ & $9 / 9.3$ & $9 / 9.3$ \\
HumCD4 & $6 / 10$ & $6 / 10$ & $6 / 10$ & 10 \\
HumF13B & $\mathbf{8 / 1 0}$ & $8 / 10$ & $8 / 10$ & $8 / 10$ \\
HumFES & $10 \mathrm{a} / \mathbf{1 1}$ & $10 \mathrm{a} / 11$ & $10 \mathrm{a} / 11$ & 11 \\
HumACTBP2 & $\mathbf{N} 28 / \mathbf{N} 31 / \mathrm{N} 33$ & $\mathrm{~N} 31 / \mathrm{N} 33$ & $\mathrm{~N} 31 / \mathrm{N} 33$ & $\mathrm{~N} 28 / \mathrm{N} 31$ \\
HumFGA & $\mathbf{2 1 / 2 2 / 2 2 . 2 / 2 4}$ & $21 / 22$ & $21 / 22$ & $22.2 / 24$ \\
Amelogenin & $\mathbf{X} / \mathbf{Y}$ & $\mathbf{X} / \mathrm{Y}$ & $\mathrm{X}$ & $\mathrm{Y}$ \\
\hline
\end{tabular}

\section{Results and discussion}

Amplification of the DNA was successful in all eight systems (table 1).

The extractions from blood and oral swabs of the patient resulted in identical DNA profiles (table 1). STR analysis of the unaffected liver surrounding the tumour resulted in more than two alleles in three STRs, which indicates a mixture of DNA from two sources (table 1, sample I; fig 2). Dependent on the DNA concentration, the intensity of expression of the alleles was different. As the weakly expressed alleles were also present in the recipient (table 1, sample III), we attributed this phenomenon to allelic admixture from the recipient-for example, circulating blood. Two further STRs showed an uneven distribution of their di-allelic pattern (table 1, sample I; HumCD4 and HumFES). This would also indicate allelic admixture from the recipient to the stronger expressed donor profile-that is, HumCD4 10 and HumFES 11. Alternatively preferential amplification is possible but this is unlikely to occur in STR analysis and does not occur with the protocols applied if both target DNA molecules are in equal concentrations.

From this, we have tentatively reconstructed the donor's profile (table 1, IV). The STR profile obtained from the carcinoma (table 1 , sample II) was either one allelic (VWA) or two allelic (other systems) and showed a full match with the pattern obtained from the recipient (table 1, sample III). There existed only one irregularity in the amelogenin system that was $\mathrm{X}-\mathrm{Y}$ (strong $\mathrm{X}$ with a weak $\mathrm{Y}$ ) in the carcinoma (fig 2) and which we attributed to the presence of very small amounts of donor DNA. Such deviation from the overall pattern as shown in sample II with no further indication of admixture is possible because: compared to other STRs, amelogenin has smaller fragment sizes of 106 and 112 base pairs for the $\mathrm{X}$ and $\mathrm{Y}$ fragment, respectively, and is therefore quantitatively more resistant to heavy degradation; and amelogenin is extremely sensitive especially in unequal mixtures and thus superior to other STR systems. There exists a mismatch of the DNA profile from the tumour tissue compared to the carcinoma free liver tissue of the donor (table 1, samples I and II), which provides strong evidence that both samples originate from different individuals. However, there exists a match between the DNA extractions from sample II and the original samples from the patient. As the matching profile is extremely rare in white people (frequency of 1 in
Figure 2 Comparison of various tissues in three STRs (A, HumVWA; $B, H u m F G A$;

C, HumACTBP2), and in the amelogenin system (D), 1, buccal mucosa; 2 , blood; 3, carcinoma tissue; 4 , liver tissue; $L$, ladder composed of different alleles (allelic ladder); M, 123 base pair size marker.

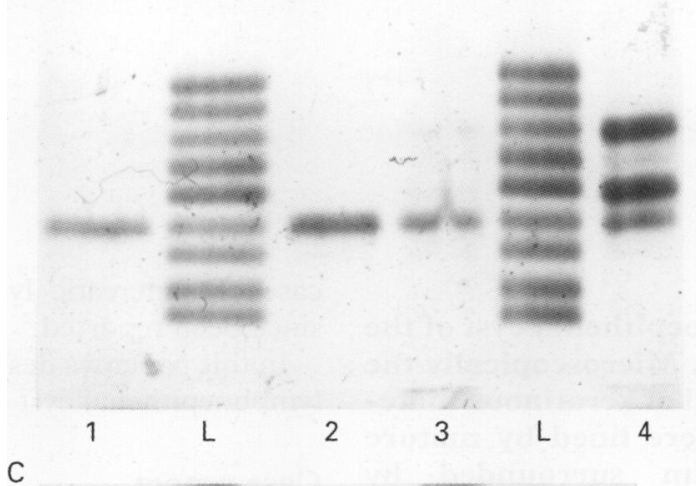

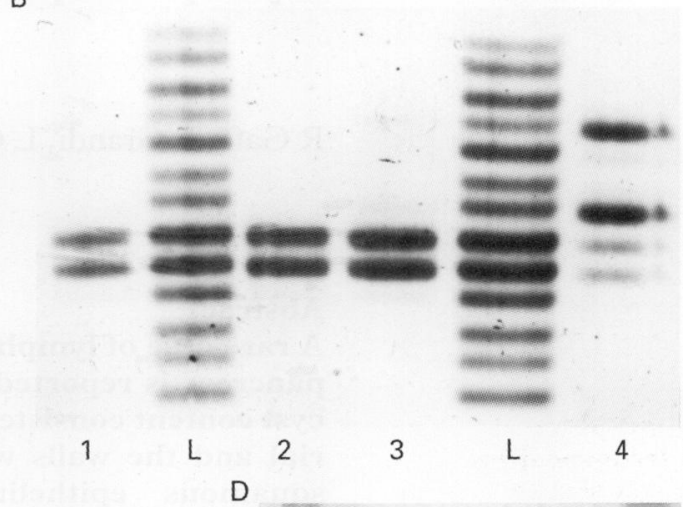


$1.25 \times 10^{7}$ individuals) this can be regarded as evidence that the de novo tumour originated from the patient and is therefore a metastasis of the original hepatocellular carcinoma. The alternative would be that the carcinoma had originated from the donor liver, which for statistical reasons is extremely improbable. Also biologically, the DNA profile IV would have needed to be converted into profile II, which would necessitate a series of single and multiple step mutations that has not yet been observed.

We suggest that if such questions arise after organ transplantation, STR analysis can be performed. It is also recommended that a blood drop from the donor should be made on cotton and stored over several years to serve as a control for related questions. In a case with a sex mismatched transplantation, fluorescent in situ hybridisation is an alternative method of investigation $^{14}$; however, the STR approach presented here allowed discrimination of the tumour origin independent of the sex of the donor and the recipient.

1 Craig J, Fowler S, Burgoyne LA, Scott AC, Harding HW. Repetitive deoxyribonucleic acid (DNA) and human genome variation. A concise review relevant to forensic biology. F Forensic Sci 1988;33:1111-26.

2 Hagelberg G, Sykes B, Hedges R. Ancient bone DNA amplified. Nature 1990;342:485.
3 Edwards A, Civitello A, Hammond HA, Caskey CT. DNA typing and genetic mapping with trimeric and tetrameric typing and genetic mapping with trimeric and tetram repeats. Am $\mathcal{F}$ Hum Genet 1991;49:746-56.

4 Shunzaburo I, Starzl T, Sheahan D, Yokoyama I, Demetris A, Todo S, et al. Hepatic resection versus transplantation for hepathocellular carcinoma. Ann Surg 1991;214:221-9

5 Kusnierz-Glaz CR, Schlegel PG, Wong RB, Schrieber JR, Chao NJ, Amylon MD, et al. Influence of age on the outcome of 500 autologous bone marrow transplantat procedures for hematologic malignancies. 7 Clin Oncol 1997; 15:18-25

6 Walsh PS, Metzger DA, Higuchi R. Chelex-100 as a medium for simple extraction of DNA for PCR-based typing from forensic material. Biotechniques 1991;10:506-13.

7 Jackson DP, Lewis FA, Taylor GR, Boylston AW, Quirke P. Tissue extraction of DNA and RNA and analysis by the polymerase chain reaction. 7 Clin Pathol 1990;43:449-504.

8 Wiegand P, Budowle B, Rand S, Brinkmann B. Forensic validation of the STR systems SE 33 and TC 11 . Int $\mathcal{F}$ Legal ved 1993;105:315-20.

9 Möller A, Wiegand P, Grüschow C, Seuchter SA, Baur MP Brinkmann B. Population data and forensic efficiency values for the STR systems Hum VWA, Hum MBP and Hum FABP. Int $f$ Legal Med 1994;106:183-9.

10 Möller A, Meyer E, Brinkmann B. Different types of structural variation in STRs: Hum FES/FPS, Hum VWA and Hum D21S11. Int $\mathcal{F}$ Legal Med 1994;106:319-23.

11 Barber MD, McKeown BJ, Parkin BH. Structural variation in the alleles of a short tandem repeat system at the human alpha fibrinogen locus. Int $\mathcal{F}$ Legal Med 1996;108:180-5.

12 Edwards MC, Clemens PR, Tristan M, Pizzuti A, Gibbs RA. Pentanucleotide repeat length polymorphism at the human CD4 locus. Nucleic Acids Res 1991;19:4791.

13 Mannucci A, Sullivan KM, Ivanov PL, Gill P. Forensic application of a rapid and quantitative DNA sex test by amplification of the X-Y homologous gene amelogenin. Int amplification of the X-Y homolog

14 Betz P, Baretton G, Tübel J, Nerlich A, Eisenmenger W. Morphological detection of X- and Y-chromosomes in smears and paraffin-embedded tissues using a non-isotopic in situ hybridization technique (NISH). Int 7 Legal Med 1994;107:108-10.

\title{
Lymphoepithelial cyst of the pancreas
}

\author{
R Gafă, E Grandi, L Cavazzini
}

Dipartimento di

Medicina

Sperimentale e

Diagnostica-Sezione

di Anatomia Istologia e

Citologia Patologica,

Università di Ferrara,

Via Fossato di Mortara

64/b, 44100 Ferrara,

Italy

Correspondence to:

Dr Roberta Gafã.

Accepted for publication 13 June 1997

\begin{abstract}
A rare case of lymphoepithelial cyst of the pancreas is reported. Microscopically the cyst content consisted of keratinous material and the walls were lined by mature squamous epithelium surrounded by dense lymphoid tissue. Immunohistochemistry showed diffuse reactivity for CD20 and CD3 in the lymphoid tissue and uniform positivity for cytokeratins in the squamous epithelium. Although the histogenesis of lymphoepithelial cysts of the pancreas is not understood, awareness of this lesion is helpful in differentiating it from other pancreatic cystic lesions. (F Clin Pathol 1997;50:794-795)
\end{abstract}

Keywords: pancreatic cyst; lymphoepithelial cyst

In 1985 Lüchtrath and Schriefers ${ }^{1}$ described a multilocular cyst of the pancreas histologically similar to the so called branchiogenic cysts that occur in the sides of the neck. The walls were lined by mature stratified squamous epithelium surrounded by lymphoid tissue. Only one other case of pancreatic lymphoepithelial cyst has since been reported. ${ }^{2}$

In this paper we describe a case of pancreatic lymphoepithelial cyst seen at our institute.

\section{Case report}

A 57 year old man presented with a three month history of intermittent upper abdominal pain. On admission an ultrasonographic study showed a round mass measuring $18 \mathrm{~mm}$ in diameter located in the head of the pancreas. At laparotomy the cyst was removed and the rest of the pancreas showed no abnormality. The postoperative course was uneventful.

\section{GROSS EXAMINATION}

The cyst measured $25 \mathrm{~mm}$ in diameter and had a smooth inner surface and a thin outer fibrosis layer. When it was opened it consisted of a single loculus filled with tan-grey material.

MICROSCOPIC EXAMINATION

Histological examination showed that the cyst was filled with keratinous material and the walls were lined by keratinising squamous epi- 